\title{
Does leader humility matter? Effects on altruism and innovation
}

Purpose. This research analyses the effect of leader humility in firm innovativeness. The study highlights the importance of promoting altruism within organisations as a mechanism that may explain why leader humility fosters innovation.

Design/methodology/approach. The study was conducted in a sample frame of 11,594 Spanish companies. 568 valid questionnaires were obtained and 284 different companies participated in the study. Structural equations were used to validate the proposed hypotheses.

Findings. All the hypotheses proposed in the conceptual model were confirmed. Results provide empirical evidence of the positive relationship between leader humility and firm innovativeness, as well as the mediating role played by altruism. In other words, leader humility promotes altruism and, in turn, firm innovativeness.

Research limitations/implications. The sample of companies is heterogeneous in terms of firm turnover, size, export ratio and age. The study is focused on firm innovativeness and only studies altruism as a mediating variable in the relationship between leader humility and firm innovativeness.

Practical implications. The present study provide some guidelines which may help companies to improve their competitiveness, enhancing workplace conditions.

Originality/value. There are few empirical studies that analyse the effect of humble leaders or leader humility on innovation. The main value of the present research is to further the current knowledge of this relationship by disentangling the mediating effect of altruism within organisations.

Paper type: Research paper.

Keywords: humility; humble; leadership; altruism; innovation; innovativeness 


\section{Introduction}

During the latest years, a great deal of research has highlighted the importance of innovation for organisations (e.g., Jia et al., 2018; Prasad and Junni, 2016). In a turbulent, extremely dynamic and globalised context, innovation may help companies to improve their competitive position, respond to rivals, as well as to enhance financial and non-financial results. Therefore, innovation is a gateway to boost organisational performance and remain competitive (Lam, 2005). As a result, numerous studies try to analyse which are the mechanisms that promote innovation (e.g., Khalili, 2016).

The present research is part of the trend of studies that disentangle the antecedents of innovation within organisations. Precedent research found evidences of different facilitators for innovation to occur, such as appropriate information systems (Domínguez-Escrig et al., 2018a), leadership style (Oke et al., 2009) or organisational learning (Jimenez-Jimenez et al., 2008), to name but a few. Among the enablers of innovation within companies, leadership plays an essential role (Prasad and Junni, 2016). Consequently, many studies have focused on the function of leaders to promote a proper environment that may lead to innovation (e.g. Domínguez-Escrig et al., 2016; Jia et al., 2018; Prasad and Juni, 2016).

In the latest decades, the need for a change in management and leadership styles in business is evident. In this sense, some authors have identified some problems in contemporary organizations: for example, abusive supervision (Liao et al., 2012; Mitchell \& Ambrose, 2007), unethical leadership (Brown \& Mitchell, 2010), leader toxicity (Pelletier, 2010), destructive leadership (Krasikova et al., 2013), petty tyranny (Kant et al., 2013) and social isolation and alienation in the workplace (Sarros et al., 2002). Economic or environmental scandals, inappropriate behaviors within companies or unacceptable human resource management policies are reported more frequently (Sendjaya et al., 2008). So, toxic and harmful workplaces are becoming unnecessarily common in the organisational context, limiting the 
competitiveness of companies and organisations. As a consequence, a loss of confidence in the business world has spread in society and an interest in improving workplace conditions has arisen. Employees demand more friendly work centres, managers want to improve results and academics try to find ways to satisfy both objectives.

Therefore, companies have to be managed in a different way and new leadership styles are required to face this demand. In this context, different leadership theories based on human values are gaining ground (Mallén et al., 2015). Leadership styles that focus on others wellbeing and consider long term consequences of organisational activity, such as servant or ethical leadership, have been positively related to both innovation and performance (Yidong, and Xinxin, 2013; Yoshida et al., 2014). However, these styles are too broad, as they include many dimensions. Consequently, it is difficult to understand how they lead to different results. As a response to this situation, Yukl (2012) suggested to study how specific leader behaviors affect different outcomes. This approach has been followed to study the effect of leaders' behaviors on innovation (Domínguez-Escrig, et al., 2018a; Mallén et al., 2015). Therefore, the present research follows this trend and analyses the influence of leaders' humility on innovation.

The study of humble leaders is not arbitrary. Although humility is often considered to be at odds with common business practice (Frostenson, 2016), several scholars have devoted substantial attention to this topic in recent years (for example, Li et al., 2016; Morris et al., 2005; Ou et al., 2018; Owens et al., 2013). On one hand, humility has been highlighted as one means to fight against corporate scandals, selfish behaviors or narcissism, which may lead leaders to make bad decisions; on the other hand, in a dynamic and complex environment, it is almost impossible for leaders to know every variable that may affect their business, so humility may help to manage success and failure by understanding and considering other points of view (Owens and Heckman, 2012). 
Owens and Heckman (2012) stated that leader humility may be a powerful means to improve organizational performance; however, little is known about the outcomes of such behavior and what influences its effectiveness. These authors highlighted that most of the literature about this topic is speculative, and there is a lack of qualitative and quantitative research that may support previous ideas suggested in the literature about the characteristics and benefits of humble leaders. In addition, recent research demands to keep studying the underlying mechanisms through which humility has its effects in organisations (Gonçalves and Brandão, 2017; Nielsen and Marrone, 2018).

Recently, some research has focused on the effect of leader humility in team innovation or employee innovation behavior. These studies have highlighted the importance of considering mediating variables in the relationship between leader humility and innovation (e.g. Liu et al., 2017; Zhou et al., 2018). In fact, when studying the influence of leadership on innovation it is essential to consider other variables that may affect this relationship, because they help to understand why the effects of leaders on innovation may lead to different outcomes (e.g. Rosing et al., 2011). A good way to understand how leadership influences innovation is to consider how the organisational context affects this relationship. Considering that humble leaders may promote an organisational context in which helpfulness, cooperation and prosocial behaviors arise, the present research analyses the mediating effect of altruism in the organisation as a mediating variable in the relationship between leader humility and firm innovativeness. Altruism in the organisation is conceptualised as those discretionary behaviors that have the effect of helping another person with an organizationally relevant task or problem (Organ, 1988).

Summing up, as innovation is a risky project, related to many uncertainties, it is important to find out which mechanisms help companies to successfully develop innovative projects. To this end, a conceptual model that analyses the influence of leader humility on altruism and, in turn, on firm innovativeness has been proposed. Following Calantone et al. (2002), firm 
innovativeness has been conceptualised as the willingness of organisations to try new ideas, and seek out new ways of doing things. It also measures the creativity in their methods of operation, and the extent of being the first in the market with new products and services. Taking into account a sample frame of 11,594 Spanish companies according to a list published by the Ministry of Economy and Competitiveness of Spain, an empirical analysis was conducted, through structural equation models, to validate the proposed hypotheses.

\section{Literature review and hypotheses}

\subsection{Leader humility}

Recent studies have pointed out the importance of leader humility and have contributed to add more theoretical and empirical rigor to the concept (e.g., Argandona, 2015; Nielsen and Marrone, 2018; Wang et al., 2018).

Humility is often spurned as inappropriate in someone who holds a position of leadership (Tangney, 2000). However, new theoretical and empirical approaches in psychology and in business ethics have considered humility as a strength of the person, instead of as a weakness. According to Argandona (2015, p. 63), humility is a "fundamental quality of a good manager and good management". The study of humble leadership gives new insights of collaborative behaviors, information sharing and joint decision making that are necessary for performance in today's complex and dynamic work environments (Ou et al., 2014).

Humility has been considered as an essential dimension of servant leadership, so it appears as an important trait in the conceptualisations proposed by different authors. Other positive leadership theories, such as level 5 leadership, participative leadership (Owens and Heckman, 2012) and authentic leadership (Nielsen and Marrone, 2018) also consider humility as an important leadership virtue. 
Nielsen and Marrone (2018) developed a systematic review of the concept of humility and identified three key components that emerged consistently in the literature: (1) accurate selfawareness (which could be equited to the intra-personal dimension of humility, suggested by Argandona, 2015); (2) an appreciation of others and their strengths and contributions; (3) openness to feedback/teachability. The latter two components are comparable to the interpersonal dimension of humility (Argandona, 2015).

The first component, labelled as "accurate self-awareness" by Nielsen and Marrone (2008), refers to the willingness to see oneself accurately. According to Rodríguez-Carvajal et al. (2014), humility is "the ability to value with the appropriate perspective, one's own talents and achievements, realizing that no-one is infallible and we all make mistakes". Humble leaders have realistic views of themselves and their capabilities and admit their mistakes and limitations, which also includes to admit failures and weaknesses to their superiors and bosses. Van Dierendonck and Nuijten (2011) considered that humility involves an appropriate understanding of someone own strong and weak points. That means not viewing oneself as better or worse than others. Through such behavior, leaders may acknowledge their limitations and overcome weaknesses thanks to the contribution and advice they find in other people.

The other components identified in the literature are "an appreciation of others and their strengths and contributions" and "openness to feedback/teachability". These latter components are related to the willingness to acknowledge and accept the views and feedback of others. These leaders may learn from criticism, even when the critics come from their own supervisors. They also learn from others' points of view and take into account opinions of people who think in a completely different way. These leaders try to have an open mind, learning from criticism and suggestions from others. Van Dierendonck and Patterson (2015) considered that humility is one of the virtuous traits of leadership that underlies an orientation to others. These leaders are not focused on themselves but on the others, the followers, and 
involves the idea of serving other people, which is an idea not very common in the leadership of business contexts. For this reason, Van Dierendonck and Patterson (2015) stated that this behavior should not be considered a weakness. Additionally, these leaders consider and listen to the advice of others, building up a leadership style less dictatorial.

According to recent research, there is empirical evidence about the positive effects of leader humility on different outcomes. This stream of literature contributes to understand why, how and when humble leaders are more effective in the context of a team or an organization. In this vein, some studies have revealed and explained the positive effect of leader humility on variables such as team performance (e.g., Owens and Hekman, 2012; Rego et al., 2017), team effectiveness (Rego et al., 2018) or firm innovation (e.g., Zhang et al., 2017; Zhou and Wu, 2018).

Owens and Heckman (2012, p.789) gathered up some of the characteristics of these leaders that have been proposed by academics and scholars such as, self-awareness, openness to new ideas, tendency to transcend oneself, willingness to understand the self, or orientation towards others. These authors suggest some positive effects in the organisational context. As it promotes a less self-interested behavior, it may increase trust in the leader among followers, improve decision-making or boost organisational commitment of employees and followers. Other scholars have highlighted other characteristics of humble leaders, such as a readiness to concede faults, to ask for advice and an orientation towards teamwork (e.g., Collins, 2001; Vera and Rodriguez-Lopez, 2004) and the effects of these behaviors on improved efficiency, learning cultures or better working groups. Likewise, Owens and Hekman (2016) demonstrated that leader behaviour can spread via social contagion to followers, producing an emerging state focused on progressively striving toward achieving the team's highest potential, which ultimately affects team performance. 
With regard to innovation outcomes, Zhang et al. (2017) explored the coexistence of two seemingly contradictory CEO traits, humility and narcissism, and how these traits complementarily create conditions for innovation. Zhou and $\mathrm{Wu}$ (2018) widened our knowledge of the relationship between humble leadership and employee innovation behaviour, studying the mediating or moderating role of other variables, such as core selfevaluation (mediator) and the leader's political skill (moderator).

Other academics, such as Carnevale et al. (2019) or Mao et al. (2018) have theorized and empirically revealed how and when leader humility promotes followers' helping attitudes and prosocial behaviors. Carnevale et al. (2019) showed that humble leaders motivate their followers to engage in helping behaviour by fostering a sense of shared identity, but this effect is only significant in the presence of high LMX-differentiation. Mao et al. (2018) explored the underlying psychological mechanisms (follower self-expansion and self-efficacy) that explain the relationship between leader humility and task performance.

There is also extensive research showing the effects of leader humility at the individual level, promoting positive outcomes such as job satisfaction or work engagement (e.g., Owens et al., 2013; Owens et al., 2015) as well as followers' helping behaviors (e.g., Carnevale et al., 2019).

\subsection{Altruism}

Altruism is a voluntary act which may be considered as the willingness to help others without considering the effects that this action may have in oneself. Additionally, no rewards are expected when being altruistic (Simmons, 1991). In the conceptualisation proposed by Podsakoff et al. (1990), altruism involves helping people in different circumstances such as helping people who has been absent by some reason, help colleagues who are overworked, help new workers to integrate in the company even when there is not an obligation to do this 
task, help people who experience problems; or be ready to give a hand to those who may need it.

Organ (1988) differentiated between altruism and courtesy by stating that altruism involves helping someone who has already a problem, while courtesy is acting in advance to avoid or mitigate problems.

\subsection{Leader humility and altruism}

Owens and Heckman (2012) stated that humility is one of the organisational virtues that may promote prosocial or altruistic behaviors, and Van Dierendonck and Patterson (2015) stated that humility entails a focus on others. Carnevale et al. (2019) provided empirical evidence showing that humble leaders motivate their followers to engage in helping behaviors. By being less self-interested, these leaders may promote, among followers, trust in leaders, commitment and engagement with the organisation, supportive relationships or unselfish behaviors among employees. Consequently, in this context, it is possible to promote organisations in which a sense of helping others or concern for other people arises.

Humility may strengthen social relationships, among other mechanisms, through helpfulness (Nielsen and Marrone, 2018). Research has found evidences that humble people are more helpful than less humble people (LaBouff et al., 2012), so they are likely to be regarded by others as more cooperative (Nielsen and Marrone, 2018). This may be considered by followers as a role model and an ideal to achieve, promoting within the organisation, altruism or altruistic behaviors.

On the other hand, humble leaders admit their weaknesses and are open to listen to the advice of others. They recognise their limitations and request followers to help them, who find that their advice is valuable (Owens and Heckman, 2012). This may motivate followers to 
participate and engage in helping behaviors, as they feel useful helping others. Owens (2009) suggested that humble leaders encourage followers to engage in prosocial behaviors emphasizing support and cooperation. Consequently, a participative environment in which employees try to help others, may be promoted through leader humility. As a result, we propose the first hypothesis of our study.

H1: Leader humility has a positive effect on altruism

\subsection{Altruism and firm innovativeness}

Altruism may be considered a helping behavior that entails a concern for others (Guinot et al. (2016). When employees are motivated by prosocial behaviors, they go beyond their responsibilities, improve their productivity and performance (Grant, 2008) and stimulate their creativity (Grant and Berry, 2011). By perceiving that their work benefits others, they are more engaged, dedicated and develop extra role behaviors. Consequently, they are inclined to create new and useful ideas that may be positive for others (Grant and Berry, 2011).

Previous research studied the effect of altruism on processes that may potentially boost innovation in the organisations. For instance, Guinot et al. (2016) found that altruism within organisations may promote organisational trust and organisational learning capability. Van Direndock and Nuijten (2011) suggested that organisational contexts characterized by trust help employees to feel safe to make mistakes, take decisions and question current patterns, which may lead to the development of innovations. On the other hand, altruism also facilitates dialogue, communication, experimentation, risk taking and participative environments. These elements have been highlighted in the academic literature as potential elements that enhance innovation (e.g. Domínguez-Escrig et al., 2016). 
On the other hand, another line of research directly analysed the effect of altruism on innovation. For instance, Domínguez-Escrig et al. (2016) found that altruistic behaviors of leaders may promote radical innovation within the organisations, highlighting the underlying effect of organisational learning. Salas-Vallina (2018) also found evidence of the relationship between altruistic leadership style and innovative behaviour in the context of public hospitals. Thus, we can pose our second hypothesis.

H2: Altruism has a positive effect on firm innovativeness

\subsection{Leader's humility and firm innovativeness: the mediating role of altruism}

Humble leaders admit that they are not perfect, make mistakes and fail, so they are open to get advice from other people (Owens and Heckman, 2012) and to new information, ideas or paradigms (Vera and Rodriguez-Lopez, 2004), including contrary ideas and criticisms (Rego et al., 2016). Since humble leaders are aware of their own limitations and weaknesses, they are eager to improve themselves (Ou et al., 2018). Humble leaders prefer inclusive, collaborative and flexible decision-making processes (Nielsen and Marrone, 2018). Consequently, they may promote an organisational environment that allows dialogue, debate and communication, through which employees may rethink current patterns, propose new ideas or be creative, boosting innovation. These leaders also take the responsibility of the mistakes made by their teams, so it may promote a feeling of safety between their subordinates who may be more willing to experiment, take risks or accept the uncertainty that involves the development of any type of innovation.

In addition, humble leaders spotlight follower's strengths and contributions, and give them freedom to take decisions and focus on work related tasks (Owens and Heckman, 2012), which may facilitate bringing and supporting new and innovative ideas. On the other hand, as these leaders are open to listen to new ideas and are receptive to feedback, they facilitate the 
conditions for learning, which has been highlighted by previous research as an essential element that fosters innovation (e.g. Domínguez-Escrig et al., 2016).

Recent studies have empirically shown how leader humility positively influences innovation within organisations. For instance, Zhou et al. (2018) found that humble leadership has a positive effect on employee innovative behavior thanks to the mediating effects of core selfevaluation and the moderating effects of leader political skills. Liu et al. (2017) found that leader humility fosters team innovation by fostering team voice climate. These studies highlight the importance of mediating variables to explain the relationship between leader humility and innovation.

Given that leader humility may promote helpfulness, prosocial behaviors or cooperation among employees within the organisational context, and that, in turn, altruistic behaviors are beneficial to promote innovation, the last hypothesis of this study is proposed.

H3: The relationship between leader humility and firm innovativeness is mediated by altruism.

INSERT FIGURE 1 ABOUT HERE

\section{Research methodology}

\subsection{Data collection}

The study was conducted in Spain considering a sample frame of 11,594 Spanish companies included in a database provided by the Spanish Ministry of Economy and Competitiveness. 
The fieldwork was carried out in 2015 and a total of 568 completed questionnaires from 284 different companies were obtained. In each one of them, we interviewed by telephone both human resources managers and general managers, so we obtained two questionnaires per company.

To tackle common method bias, human resources managers answered the questions related to humility and altruism, while general managers answered the questions about firm innovativeness. These two kinds of managers were selected because their experience and position within their companies makes them a reliable source of information, as they have an overall view of what happens in their organisations. In addition, the anonymity of the participants in the study was guaranteed.

A 7-point Likert scale (from 1, totally disagree, to 7, totally agree) was used to measure the different scales that make up this study. By doing this, it is possible to analyse the degree of agreement or disagreement with each statement included in the questionnaire.

Given that the study is focused on Spain, all the questions were posed in Spanish. The scale that measured leader humility was originally developed in Spanish, while the scales related to altruism and firm innovativeness were created in English. To guarantee the accuracy of the translation, a double-back technique was followed with all the variables and statements that made up the questionnaire.

\subsection{Measurement instruments}

The reliability of the scales was determined by Cronbach's alpha, compound reliability, and average mean extracted (Table 2). 
Leader humility was measured with the scale developed by Rodríguez-Carvajal et al. (2014); the construct was reliable with a Cronbach's alpha of 0.92. Altruism was measured through the scale of Podsakoff et al. (1990); the reliability was assured with a Cronbach's alpha of 0.95. Finally, firm innovativeness was based on the work by Calantone et al. (2002); the Cronbach's alpha of this scale was 0.81 .

\subsection{Control variables}

Number of employees, turnover, company's age and export ratio (export sales/total sales) were considered as control variables. These variables have been highlighted by previous research by having a potential influence on innovation so it is worth to control for their influence on firm innovativeness in the present study.

Regarding the number of employees, the sample is distributed as follows: fewer than 25 employees (31.0\%), 26-50 employees (40.8\%), 51-75 employees (14.1\%), 76-100 employees (6.3\%), and more than 100 employees (7.8\%).

With respect to annual turnover, the companies in the sample are classified as follows: less than 1 million euros (12.0\%), 1-2.5 million (22.5\%), 2.5-5 million (35.9\%), 5-10 million (20.1\%), and more than 10 million (9.5\%).

According to their age, companies have the following distribution: until 10 years $(12.3 \%), 11$ 25 years $(50.0 \%)$, $26-50$ years $(29.6 \%)$, and more than 50 years $(8.1 \%)$.

Finally, regarding the export ratio, the sample has the following distribution: less than $10 \%$ (31.7\%), $11-25 \%$ (19.4\%), $26-50 \%$ (33.8\%), $51-75 \%(9.8 \%)$, and more than $75 \%(5.3 \%)$. 
Structural equations and the statistical software AMOS-23 were used to empirically validate the proposed model (Figure 1). In this model, we analyse the mediating role played by altruism in the relationship between leader humility and firm innovativeness. It also includes the following effects: the effect of leader humility on altruism, the effect of altruism on firm innovativeness, and the indirect effect of leader humility on firm innovativeness. We opted for the maximum likelihood estimation method. Additionally, a bootstrapped confidence interval was used to validate the proposed indirect effect.

\section{Results}

\subsection{Descriptive statistics and psychometric properties of the measurement scales}

Table 1 provides information of the means, correlations and standard deviations in each construct. Before using structural equation modeling to test the hypotheses, it was studied the dimensionality and reliability, as well as convergent, discriminant and content validity of the measurement scales (Tippins and Sohi, 2003), to determine the validity of the constructs.

Additionally, a full measurement model that includes all the variables was tested (Anderson and Gerbing, 1988). The aim of this model is to establish the structure of the variables in the context of other variables measured in the study. It helps to ensure that the measures are different from one another. The overall fit of this model was: Chi square (d.f.) $=178.88$ (62); $p$ $=0.00 ; \mathrm{CFI}=0.97 ; \mathrm{RMSEA}=0.07$; confirming that the constructs were different from one another.

Table 2 provides information of the reliability analysis. The results are satisfactory. Cronbach's alpha values are above the minimum accepted value of 0.7 (Nunnally, 1978). The same is 
true for those values of composite reliability. Besides, the average variance extracted in all the constructs is above the minimum recommended value of 0.5 (Nunnally, 1978).

Content validity is supported because all the measurement scales were used and validated in previous research. The variables used to measure firm innovativeness were based on the work by Calantone et al. (2002). Leader humility is based on the scale by Rodríguez-Carvajal et al. (2014). Finally, altruism was measured using the scale developed by Podsakoff et al. (1990).

Convergent validity was evaluated through the average variance extracted (Fornell and Larcker, 1981), the Bentler-Bonett coefficient, and the magnitude of the factor loadings. Average variance extracted is above the minimum value of 0.5 for all the constructs; the values of BBNFI reached or exceeded 0.9 in all the constructs; while the magnitude of factorial loadings is above 0.5 for all the constructs. Consequently, the convergent validity of all the constructs that make up this study is supported.

Finally, to evaluate discriminant validity, the average variance extracted must be greater than the square root of the construct correlations, thereby suggesting that each construct is more strongly related to its own measures than to others.

INSERT TABLE 1 ABOUT HERE

INSERT TABLE 2 ABOUT HERE 
New trends in mediation analysis do not require evidence of a total effect to estimate direct and indirect effects (Hayes, 2012). However, the results of the total effect were statistically different from zero $(c=0.22, t=3.28, p<0.00)$. Different conditions must be met to support the mediation: 1) if there is a significant relationship in the total effect model (relationship between leader humility and firm innovativeness), this must decrease considerably or become non-significant in the mediation model; (2) the mediation model must explain more variance in the dependent variable (firm innovativeness) than the total effect model; (3) a significant relationship between leader humility and altruism innovation is necessary; and (4) in addition, the relationship between altruism and firm innovativeness must be significant. On the other hand, bootstrapping has to be conducted to test the significance of the mediated effect (Hayes, 2013; MacKinnon et al., 2012).

All the conditions proposed in the former paragraph were met. Consequently, the mediating role of altruism in the relationship between leader humility and firm innovativeness was confirmed: (1) the significant relationship between leader humility and firm innovativeness becomes non-significant when it includes the mediating effect of altruism ( $c 1=0.08, t=1.03$, $p>0.05)$; (2) the mediated model explains more variance than the total effect model $(0.13 \mathrm{vs.}$ $0.05)$; (3) there is a significant relationship between leader humility and altruism $(a=0.46, t=$ 7.13, $p<0.00$ ), confirming Hypothesis $1 ;(4)$ and between altruism and firm innovativeness (b $=0.32, \mathrm{t}=4.23, \mathrm{p}<0.00)$, which confirms Hypothesis 2 . Finally, the estimated indirect effect of leader humility on firm innovativeness is 0.15 . The $95 \%$ bias-corrected confidence interval for the indirect effect based on a 5,000 bootstrap sample was entirely above zero $(0.07$ to 0.23). Consequently, the indirect effect of leader humility on firm innovativeness is significantly different from zero, and so the null hypothesis of no mediation can be rejected. Therefore, Hypothesis 3 is confirmed. 
Regarding the control variables, none of them has a significant effect on firm innovativeness (turnover: $\mathrm{d} 1=0.17, \mathrm{t}=0.84, \mathrm{p}>0.05$; number of employees: $\mathrm{d} 2=-0.20, \mathrm{t}=-0.95, \mathrm{p}>0.05$; firm age: $d 3=-0.01, t=-0.19, p>0.05$; export intensity: $d 4=0.03, t=0.42, p>0.05$ )

\section{INSERT FIGURE 2 ABOUT HERE}

\section{INSERT FIGURE 3 ABOUT HERE}

\section{Discussion}

The scandals and inappropriate behaviors that have marked the business field in the latest decades have provoked an increasing demand of new management and leadership styles which promote a change towards more fair, sustainable and efficient organisations. In addition, the competitive context, extremely turbulent and dynamic, also requires different approaches in the way organisations are managed, as they need to be more flexible, adaptive and innovative. To this end, the present study has focused on humility, as a leader behavior that may facilitate organisational contexts that gather the necessary conditions to compete.

The main value of the study is in the mediating effect of altruism in the relationship between leader humility and firm innovativeness. Altruism, as a prosocial behavior, has raised the interest of a great deal of research as a means to improve organisational outcomes in the context of fairer and more sustainable organisations. Although leader humility has been recently related to innovation, the study of this relationship seems to be in the first stages of development, so through this research, we have tried to further progress towards a complete understanding of the mechanisms that explain this relationship. In addition, we hope that this 
research may serve as an incentive to continue empirically analysing the effects of leader humility on different outcomes.

Results confirmed all the hypotheses proposed in the study. Firstly, leader humility has a positive effect on altruism; secondly, altruism has a positive effect on firm innovativeness; and finally, we found evidence of the mediating role played by altruism in order to explain the positive effect of leader humility on firm innovativeness.

On the basis of the results obtained, the present research has theoretical implications in the fields of leader humility, altruism and firm innovativeness. This study contributes to the leadership literature by demonstrating the positive influence of leader humility to promote altruistic organisational contexts that may improve firm innovativeness. Previous research analysed the effect of humble leaders on employee innovative behavior and team innovation, but neither had analysed its effect on innovation as an organisational outcome. In addition, to the best of our knowledge, this is the first time that altruism has been empirically analysed as an outcome of humility in leadership, and consequently as the underlying mechanism that fosters innovation.

The study has also implications in the literature about altruism in the business fields. In this case, we analysed altruism as a contextual factor within organisations. In this vein, the results help to widen the understanding of the elements that promote organisational contexts in which altruism arises. It also sheds light on the potential benefits of altruism, as a facilitator of innovation in organisations.

Finally, the study enhances the literature about facilitators or promoters of innovation in the organisation. Although there is a vast number of studies that try to disentangle the mechanisms that promote innovation, there is a need to understand how new leadership styles, prosocial or helping behaviors may facilitate innovative and creative organisations. The 
objective is to improve organisational results by showing a sincere concern for the welfare of others, the future of society and sustainability. The present research tries to give new insights by highlighting the role of humble leaders and altruistic organisational contexts.

\subsection{Implications for practitioners}

This study provides some practical implications for those companies that are interested in promoting their capability to develop innovations. By promoting a leadership style that is open to ideas of other people, accept criticisms and listen to suggestions, it is possible to lay the foundations for an organisational context in which learning spreads, reflecting about your own decisions, rethinking existing patterns and proposing new and innovative ideas. In this environment, there is more freedom to accept mistakes and failures, new ideas are not censored or silenced and a participative organisational context flourishes in which employees feel confident to share their points of view.

In addition, taking into account that in these organisations new ideas are not going to be judged negatively, and proposals or suggestions will be welcomed, employees are motivated to help other people, building up organisations in which altruism or altruistic behaviors spread. When people feel that their contributions are positive or have a significant impact in others, they are likely to engage in helping behaviors, lending a hand to other colleagues in an unselfish manner.

To promote humility and altruism, it is necessary that companies and organisations focus in these behaviors and virtues when planning their human resources policies. Recruitment and selection policies should focus on detecting humility when hiring new staff. Promotion should also consider those employees who, among other characteristics, are humble in the workplace. According to Ou et al. (2014), humility can gradually change through experience or learning. Consequently, it would be interesting to develop coaching programs to teach and 
promote humility as an important value in the business field. To date, this type of behavior has been underestimate in the competitive world of organisations and companies, in which focus is on achievements and success.

On the other hand, to promote organisational contexts that foster altruism or altruistic behaviors, it would be interesting to control for those behaviors that are oriented to help other people. For example, in work climate surveys, altruism would be measured by including indicators to detect if employees help other colleagues when those experience problems or by analysing unselfish behaviors. Nowadays, organisations tend to rely on indicators related to financial and non-financial performance, however it is time to consider other variables that may be in the origin of these outcomes.

\subsection{Limitations and future research}

Finally, it must be recognised that this study has some limitations that should be overcome in the future. Firstly, this study focused on the effect of leader humility and altruism on innovations. However, the study of innovation is a wide field that includes different typologies and definitions. Future research should differentiate between typologies of innovation, namely between radical and incremental innovation. The antecedents and consequences of these typologies differ, so it would be interesting to disentangle if leader humility and altruistic organisational context may promote or hamper both of them. On the other hand, it is important to study if there are differences between product, service or process innovation, as they have been conceptualised in a different way in the academic field.

The study was conducted in Spain, so the results are limited to companies of this country. The European Innovation Scoreboard annually controls the innovative performance of countries in the European Union. In the last report, launched in 2018, Spain was considered a moderate 
innovator. Consequently, it would be interesting to compare between countries with different innovative performance (e.g. innovation leaders), in order to disentangle potential differences.

This research focused on the effect of altruism as a mediating variable to explain the effect of leader humility on firm innovativeness. However, as this is a relatively new field of study, it is necessary to consider other possible variables that may shed light in this process, such as those related to organisational learning or organisational structure.

Regarding the methodology followed to gather data, there are also limitations. For example firm innovativeness was measured using subjective data. Future studies should consider other variables such as number of innovations developed. Regarding altruism and humility, we directly asked to managers. Further research should consider the opinion of followers and employees.

Concerning future research, it could be worthy to study if humble behaviors or a certain level of them could lead to negative outcomes (Ou et al., 2014; Weidman et al., 2018). According to Bharanitharan et al. (2018), the majority of empirical research on the topic of humility has demonstrated its positive effects. However, these authors challenged the consensus and concluded that a leader's humble behaviour can have contradictory outcomes in followers' voice behavior. Future research should address if there is a tipping point from which the effects of leader humility on innovation or other outcomes are negative.

Although this study focused on leader humility, there are many other leader behaviors that demand more interest in the current competitive context such as stewardship, forgiveness or accountability. Further research should expand the knowledge related to the antecedents and consequences of these behaviors. 
Finally, this research gathered data from a heterogeneous sample frame in terms of firm age, number of employees, export performance of turnover. Future studies should be conducted, for example, in companies with a similar size or age.

\section{References}

Anderson, J. C., and Gerbing, D. W. (1988). "Structural equation modeling in practice: A review and recommended two-step approach", Psychological Bulletin, Vol.103 No.3, pp. 411.

Argandona, A. (2015). "Humility in management", Journal of Business Ethics, Vol.132 No. 1, pp. 63-71.

Bharanitharan, K., Chen, Z. X., Bahmannia, S., and Lowe, K. B. (2018). "Is Leader Humility a Friend or Foe, or Both? An Attachment Theory Lens on Leader Humility and Its Contradictory Outcomes", Journal of Business Ethics, pp. 1-15.

Brown, M. E., and Mitchell, M. S. (2010). "Ethical and unethical leadership: Exploring new avenues for future research", Business Ethics Quarterly, Vol. 20 No. 4, pp. 583-616.

Calantone, R. J., Cavusgil, S. T., and Zhao, Y. (2002), "Learning orientation, firm innovation capability, and firm performance", Industrial Marketing Management, Vol.31 No.6, pp.515-524.

Carnevale, J. B., Huang, L., \& Paterson, T. (2019). "LMX-differentiation strengthens the prosocial consequences of leader humility. An identification and social exchange perspective", Journal of Business Research, Vol. 96, pp. 287-296.

Collins, J. (2001). "Level 5 leadership: The triumph of humility and fierce resolve". Harvard Business Review, Vol. 79 No.1, pp. 66-76. 
Domínguez Escrig, E., Mallén, F., Chiva, R., and Lapiedra, R. (2016), “How does altruistic leader behavior foster radical innovation? The mediating effect of organizational learning capability”, Leadership \& Organization Development Journal, Vol. 37 No.8, pp. 1056-1082.

Domínguez-Escrig, E., Mallén, F., Lapiedra, R., and Chiva, R. (2018b), "The influence of leaders' stewardship behavior on innovation success: the mediating effect of radical innovation", Journal of Business Ethics, pp.1-14.

Domínguez-Escrig, E., Mallén-Broch, F. F., Lapiedra-Alcamí, R., and Chiva-Gómez, R. (2018a) "Promoting radical innovation through end-user computing satisfaction", Industrial Management \& Data Systems, Vol. 118 No. 8, pp.1629-1646.

Fornell, C., and Larcker, D. F. (1981), "Evaluating structural equation models with unobservable variables and measurement error", Journal of Marketing Research, Vol.18 No.1, pp. 39-50.

Frostenson, M. (2016). "Humility in business: A contextual approach", Journal of business ethics, Vol. 138 No. 1, pp. 91-102.

Gonçalves, L., and Brandão, F. (2017). “The relation between leader's humility and team creativity: The mediating effect of psychological safety and psychological capital", International Journal of Organizational Analysis, Vol. 25 No. 4, pp. 687-702.

Grant, A. M. (2008), "Does intrinsic motivation fuel the prosocial fire? Motivational synergy in predicting persistence, performance, and productivity", Journal of Applied Psychology, Vol. 93 No.1, pp. 48-58. 
Grant, A. M., and Berry, J. W. (2011), "The necessity of others is the mother of invention: Intrinsic and prosocial motivations, perspective taking, and creativity", Academy of Management Journal, Vol. 54 No.1, pp. 73-96.

Guinot, J., Chiva, R., and Mallén, F. (2016), "Linking altruism and organizational learning capability: A study from excellent human resources management organizations in Spain", Journal of Business Ethics, Vol.138 No. 2, pp. 349-364.

Hayes, A. F. (2012), "PROCESS: A versatile computational tool for observed variable mediation, moderation, and conditional process modelling". Available at: http://www.afhayes.com/public/process2012.pdf (accessed 7 november 2017).

Hayes, A. F. (2013), Introduction to mediation, moderation, and conditional process analysis: A regression-based approach. Guilford Publications.

Jia, X., Chen, J., Mei, L., and Wu, Q. (2018). "How leadership matters in organizational innovation: a perspective of openness", Management Decision, Vol. 56 No. 1, pp. 6-25.

Jimenez-Jimenez, D., Sanz Valle, R., and Hernandez-Espallardo, M. (2008). "Fostering innovation: the role of market orientation and organizational learning", European Journal of Innovation Management, Vol. 11 No. 3, pp. 389-412.

Kant, L., Skogstad, A., Torsheim, T., and Einarsen, S. (2013). "Beware the angry leader: Trait anger and trait anxiety as predictors of petty tyranny", The Leadership Quarterly, Vol. 24 No. 1, pp. 106-124.

Khalili, A. (2016). "Linking transformational leadership, creativity, innovation, and innovationsupportive climate", Management Decision, Vol. 54 No. 9, pp. 2277-2293. 
Krasikova, D. V., Green, S. G., and LeBreton, J. M. (2013). "Destructive leadership: A theoretical review, integration, and future research agenda", Journal of Management, Vol. 39 No. 5 , pp. $1308-1338$.

LaBouff, J. P., Rowatt, W. C., Johnson, M. K., Tsang, J. A., and Willerton, G. M. (2012), "Humble persons are more helpful than less humble persons: Evidence from three studies", The Journal of Positive Psychology, Vol.7 No.1, pp. 16-29.

Lam, A. (2005), "Organizational innovation”, in Fagerberg, J., Mowery, D.C. and Nelson, R.R. (Eds), The Oxford Handbook of Innovation, Oxford University Press, Oxford, pp. 115-147.

Li, J., Liang, Q. Z., and Zhang, Z. Z. (2016). "The effect of humble leader behavior, leader expertise, and organizational identification on employee turnover intention", Journal of Applied Business Research, Vol. 32 No. 4, pp. 1145-1156.

Liu, D., Liao, H., and Loi, R. (2012). "The dark side of leadership: A three-level investigation of the cascading effect of abusive supervision on employee creativity", Academy of Management Journal, Vol. 55 No. 5, pp. 1187-1212.

Liu, W., Mao, J., and Chen, X. (2017), "Leader humility and team innovation: investigating the substituting role of task interdependence and the mediating role of team voice climate", Frontiers in Psychology, Vol. 8, pp.1115.

MacKinnon, D. P., Coxe, S., and Baraldi, A. N. (2012), "Guidelines for the Investigation of Mediating Variables in Business Research", Journal of Business and Psychology, Vol. 27, pp. $1-14$. 
Mallén, F., Chiva, R., Alegre, J., and Guinot, J. (2015). "Are altruistic leaders worthy? The role of organizational learning capability", International Journal of Manpower, Vol. 36 No. 3, pp. 271-295.

Mao, J., Chiu, C. Y., Owens, B. P., Brown, J. A., \& Liao, J. (2019). “Growing Followers: Exploring the Effects of Leader Humility on Follower Self-Expansion, Self-Efficacy, and Performance", Journal of Management Studies, Vol. 56 No. 2, pp. 343-371.

Mitchell, M. S., and Ambrose, M. L. (2007). "Abusive supervision and workplace deviance and the moderating effects of negative reciprocity beliefs", Journal of Applied Psychology, Vol. 92 No. $4,1159-1168$.

Morris, J. A., Brotheridge, C. M., and Urbanski, J. C. (2005). "Bringing humility to leadership: Antecedents and consequences of leader humility", Human Relations, Vol. 58 No. 10, pp. 1323-1350.

Nielsen, R., and Marrone, J. A. (2018), “Humility: Our Current Understanding of the Construct and its Role in Organizations", International Journal of Management Reviews, Vol. 00, pp.120.

Nunnally, J. C. (1978), Psychometric Theory, McGraw-Hill, New York.

Oke, A., Munshi, N., and Walumbwa, F. O. (2009). "The influence of leadership on innovation processes and activities", Organizational Dynamics, Vol. 38 No. 1, pp. 64-72.

Organ, D. W. (1988), Organizational citizenship behavior: The good soldier syndrome. Lexington Books/DC Heath and Com, Lexington, MA. 
Ou, A. Y., Tsui, A. S., Kinicki, A., Waldman, D. A., Xiao, Z. X., and Song, J. W. (2014). "Humble chief executive officers' connections to top management team integration and middle managers’ responses", Administrative Science Quarterly, Vol. 59, pp. 34-72.

Ou, A. Y., Waldman, D. A., and Peterson, S. J. (2018). "Do humble CEOs matter? An examination of CEO humility and firm outcomes", Journal of Management, Vol. 44 No. 3, pp. 1147-1173.

Owens, B. P. (2009)."Humility in organizational leadership", Unpublished Doctoral Dissertation. University of Washington.

Owens, B. P., \& Hekman, D. R. (2016). "How does leader humility influence team performance? Exploring the mechanisms of contagion and collective promotion focus", Academy of Management Journal, Vol. 59 No. 3, pp. 1088-1111.

Owens, B. P., and Hekman, D. R. (2012), "Modeling how to grow: An inductive examination of humble leader behaviors, contingencies, and outcomes", Academy of Management Journal, Vol. 55 No.4, pp. 787-818.

Owens, B. P., Johnson, M. D., and Mitchell, T. R. (2013). “Expressed humility in organizations: Implications for performance, teams, and leadership", Organization Science, Vol. 24 No. 5, pp. 1517-1538.

Owens, B. P., Wallace, A. S., \& Waldman, D. A. (2015). "Leader narcissism and follower outcomes: The counterbalancing effect of leader humility", Journal of Applied Psychology, Vol. 100 No. 4, 1203-1213. 
Pelletier, K. L. (2010). "Leader toxicity: An empirical investigation of toxic behavior and rhetoric", Leadership, Vol. 6 No. 4, pp. 373-389.

Podsakoff, P. M., MacKenzie, S. B., Moorman, R. H., and Fetter, R. (1990), "Transformational leader behaviors and their effects on followers' trust in leader, satisfaction, and organizational citizenship behaviors", The Leadership Quarterly, Vol.1 No.2, pp. 107-142.

Prasad, B., and Junni, P. (2016). "CEO transformational and transactional leadership and organizational innovation: The moderating role of environmental dynamism", Management Decision, Vol. 54 No. 7, pp. 1542-1568.

Rego, A., \& Simpson, A. V. (2018). "The perceived impact of leaders' humility on team effectiveness: An empirical study", Journal of Business Ethics, Vol. 148 No. 1, pp. 205-218.

Rego, A., Owens, B., Leal, S., Melo, A. I., e Cunha, M. P., Gonçalves, L., \& Ribeiro, P. (2017). "How leader humility helps teams to be humbler, psychologically stronger, and more effective: A moderated mediation model", The Leadership Quarterly, Vol. 28 No. 5, pp. 639-658.

Rodríguez-Carvajal, R., de Rivas, S., Herrero, M., Moreno-Jiménez, B., and Van Dierendonck, D. (2014), "Leading people positively: cross-cultural validation of the Servant Leadership Survey (SLS)", The Spanish Journal of Psychology, Vol. 17, pp. 1-13.

Rosing, K., Frese, M., and Bausch, A. (2011), "Explaining the heterogeneity of the leadershipinnovation relationship: Ambidextrous leadership", The Leadership Quarterly, Vol.22 No.5, pp. 956-974. 
Salas-Vallina, A., Ferrer-Franco, A., and Fernández Guerrero, R. (2018). “Altruistic leadership and affiliative humor's role on service innovation: Lessons from Spanish public hospitals", The International Journal of Health Planning and Management, Vol. 33, pp. 861-872.

Sarros, J. C., Tanewski, G. A., Winter, R. P., Santora, J. C., and Densten, I. L. (2002). "Work alienation and organizational leadership", British Journal of Management, Vol. 13 No. 4, pp. 285-304.

Sendjaya, S., Sarros, J. C., \& Santora, J. C. (2008). "Defining and measuring servant leadership behaviour in organizations", Journal of Management Studies, Vol. 45 No. 2, pp. $402-424$.

Simmons, R. G. (1991), “Altruism and Sociology”, Sociological Quarterly, Vol. 32 No.1 , pp.122.

Tangney, J. P. (2000). "Humility: Theoretical perspectives, empirical findings and directions for future research", Journal of Social and Clinical Psychology, Vol. 19 No. 1, pp. 70-82.

Tippins, M. J., and Sohi, R. S. (2003), "IT competency and firm performance: is organizational learning a missing link?", Strategic Management Journal, Vol.24 No.8, pp. 745-761.

Van Dierendonck, D., and Nuijten, I. (2011), "The servant leadership survey: Development and validation of a multidimensional measure", Journal of Business and Psychology, Vol. 26 No. 3, pp. 249-267.

Van Dierendonck, D., and Patterson, K. (2015), "Compassionate love as a cornerstone of servant leadership: An integration of previous theorizing and research", Journal of Business Ethics, Vol.128 No.1, pp. 119-131. 
Vera, D., and Rodriguez-Lopez, A. (2004), "Strategic virtues: Humility as a source of competitive advantage", Organizational Dynamics, Vol. 33, pp. 393-408.

Wang, L., Owens, B. P., Li, J. J., \& Shi, L. (2018). "Exploring the affective impact, boundary conditions, and antecedents of leader humility", Journal of Applied Psychology, Vol. 103 No. 9, pp. 1019-1038.

Weidman, A. C., Cheng, J. T., \& Tracy, J. L. (2018). "The psychological structure of humility", Journal of Personality and Social Psychology, Vol. 114 No. 1, pp. 153-178.

Yidong, T., and Xinxin, L. (2013). “How ethical leadership influence employees' innovative work behavior: A perspective of intrinsic motivation", Journal of Business Ethics, Vol. 116 No. 2, pp. 441-455.

Yoshida, D. T., Sendjaya, S., Hirst, G., and Cooper, B. (2014). "Does servant leadership foster creativity and innovation? A multi-level mediation study of identification and prototypicality", Journal of Business Research, Vol. 67 No. 7, pp. 1395-1404.

Yukl, G. (2012), "Effective leadership behavior: What we know and what questions need more attention", The Academy of Management Perspectives, Vol. 26 No. 4, pp. 66-85.

Zhang, H., Ou, A. Y., Tsui, A. S., \& Wang, H. (2017). "CEO humility, narcissism and firm innovation: A paradox perspective on CEO traits", The Leadership Quarterly, Vol. 28 No. 5, pp. 585-604.

Zhou, F., and Wu, Y. J. (2018), "How humble leadership fosters employee innovation behavior: A two-way perspective on the leader-employee interaction", Leadership \& Organization Development Journal, Vol.39 No.3, pp. 375-387. 
Table 1. Means, standard deviations and factor correlations

\begin{tabular}{lccccc}
\hline Concept & Mean & SD & 1 & 2 & 3 \\
\hline 1. Leader humility & 5.04 & 1.00 & 1 & & \\
2. Altruism & 4.62 & 1.03 & $.44^{* *}$ & 1 & \\
3. Firm innovativeness & 5.54 & 0.89 & $.16^{* *}$ & $.30^{* *}$ & 1 \\
\hline $\mathrm{n}=284$ & & & & & \\
$* * \mathrm{p}<0.01$ & & & & & \\
& & & & &
\end{tabular}

Table 2. Constructs reliability: Cronbach's alpha, composite reliability and average variance extracted.

\begin{tabular}{lccc}
\hline & $\begin{array}{c}\text { Cronbach's } \\
\text { alpha }\end{array}$ & $\begin{array}{c}\text { Composite } \\
\text { reliability }\end{array}$ & $\begin{array}{c}\text { Average } \\
\text { variance } \\
\text { extracted } \\
\text { (AVE) }\end{array}$ \\
\hline Lenstruct & 0.92 & 0.92 & 0.69 \\
Altruism & 0.95 & 0.95 & 0.78 \\
Firm innovativeness & 0.81 & 0.84 & 0.57 \\
\hline
\end{tabular}




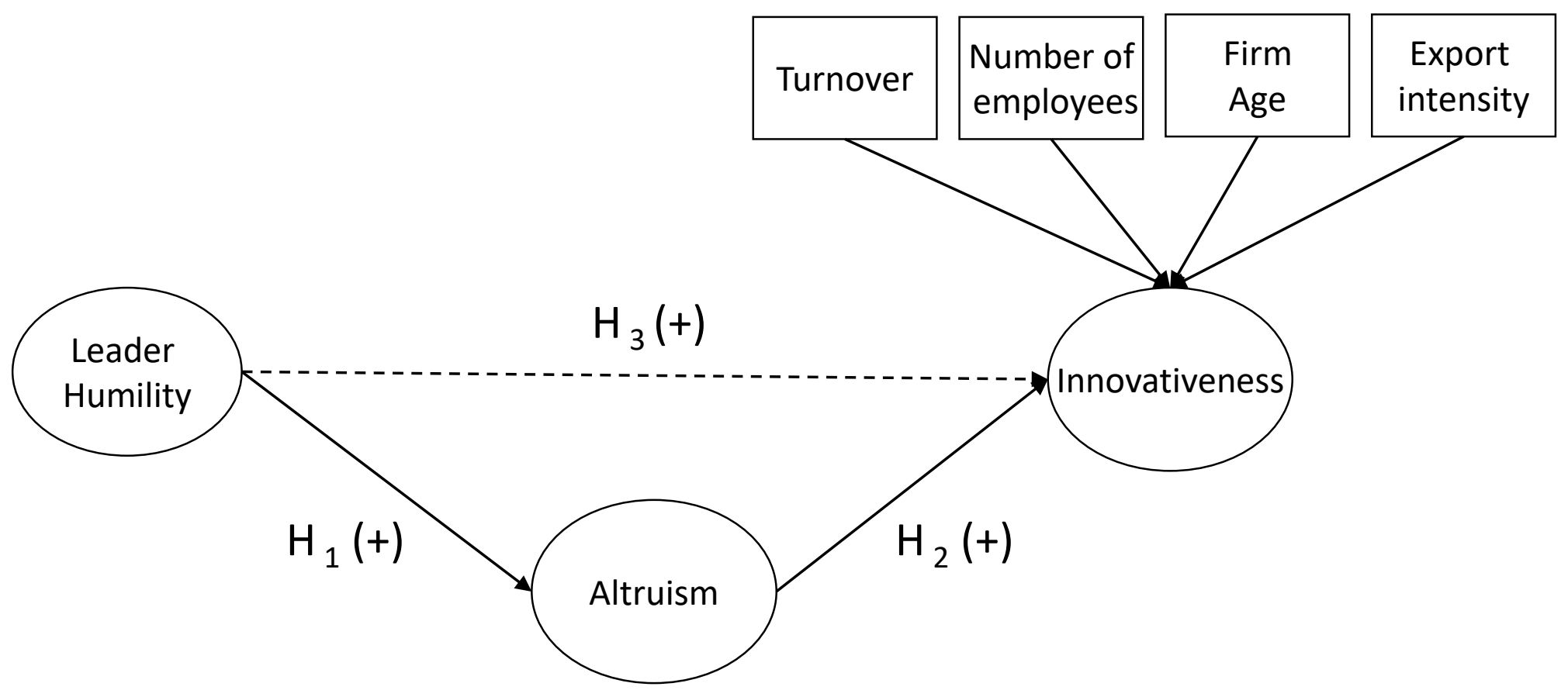

Figure 1. Conceptual model 




Figure 2. Total effect model (without the mediator) 


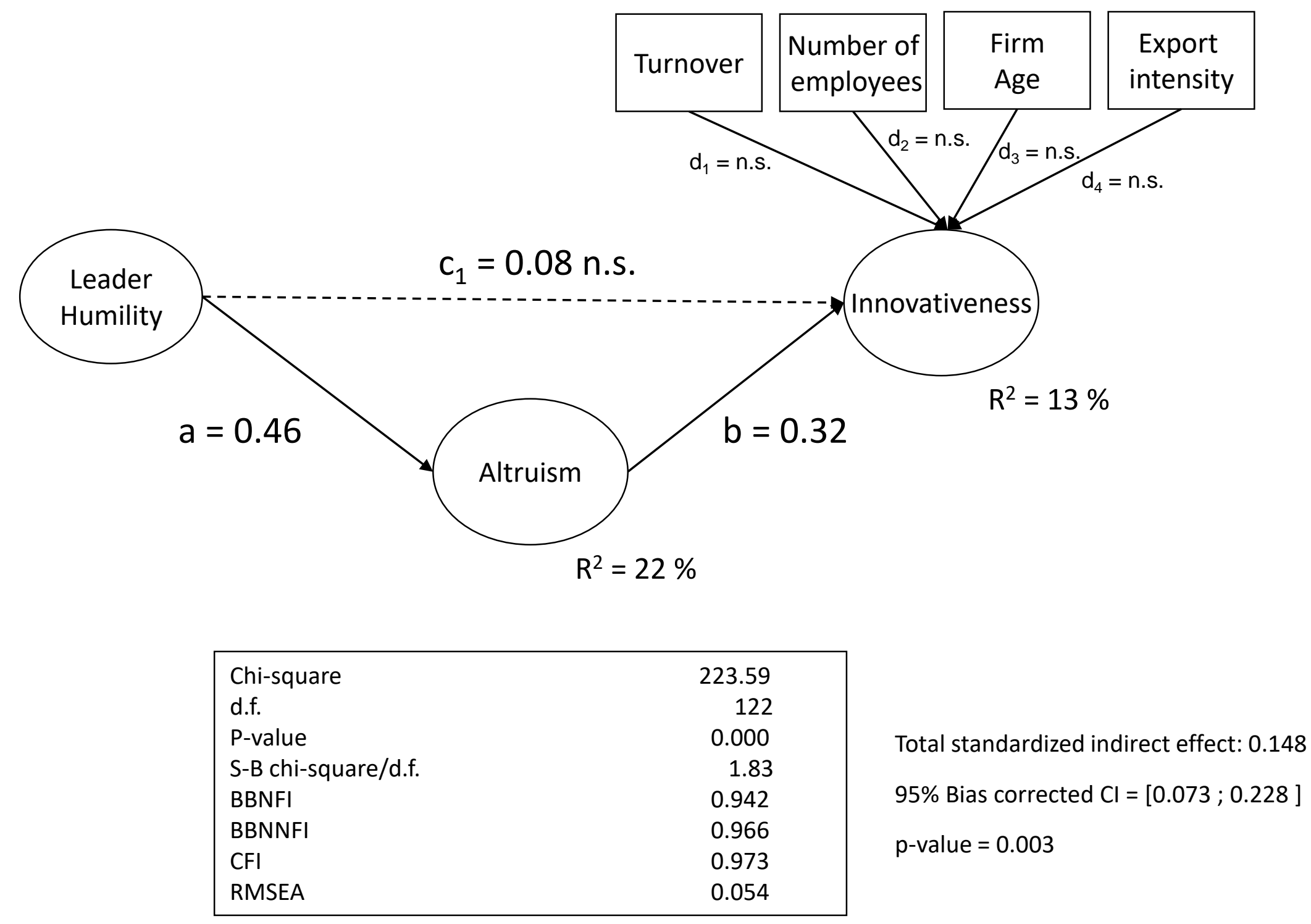

Figure 3. Results of the mediated model 